\title{
Tip60-siRNA regulates ABCE1 acetylation to suppress lung cancer growth via activation of the apoptotic signaling pathway
}

\author{
ZONGYING LIANG $^{1,2}$, QIAN YU ${ }^{1}$, HONGTAO JI $^{1}$ and DALI TIAN ${ }^{1}$ \\ ${ }^{1}$ Department of Thoracic Surgery, The Fourth Affiliated Hospital of China Medical University, Shenyang, Liaoning 110032; \\ ${ }^{2}$ Department of Thoracic Surgery, The Affiliated Hospital of Chengde Medical College, Chengde, Hebei 067000, P.R. China
}

Received June 25, 2018; Accepted December 13, 2018

DOI: $10.3892 /$ etm.2019.7302

\begin{abstract}
Lung cancer is a leading cause of cancer-associated mortality and morbidity worldwide. Previous studies have suggested that ATP-binding cassette transporter E1 (ABCE1) acetylation is upregulated in the tissues and cells of lung cancer and is associated with the prognosis of patients with lung cancer. The aim of the present study was to investigate the association between Tat interactive protein $60 \mathrm{kDa}$ (Tip60) expression and ABCE1 acetylation, and the effect of Tip60 on the biological functions of A549 lung carcinoma cells. The expression levels of Tip60 and ABCE1 acetylation were examined using western blot and co-immunoprecipitation (Co-IP) assays in normal bronchial epithelial (HBE) and human lung cancer (A549) cells. The expression of Tip60 then was downregulated in A549 cells using small interfering RNA. Wound healing and Transwell assays were used to assess cell invasion and migration. The biological effects of Tip60 in lung cancer cells were investigated using MTT and flow cytometric assays. Subsequently, tumor xenografts were established to observe the effect of Tip60 on lung cancer in vivo. Western blot and Co-IP assays were performed to investigate the mechanism of Tip60 in A549 cells. Tip60 expression and ABCE1 acetylation were upregulated in the lung cancer cells compared with the normal bronchial epithelial cells. Downregulation of Tip60 decreased the acetylation of ABCE1 and inhibited cell proliferation, invasion and migration. Furthermore, the downregulation of Tip60 activated the apoptotic pathway in order to achieve its suppressive function. In the xenografts, the tumor weight and volume were notably reduced due to the downregulation of Tip60 expression. The results of the present study strongly suggest that Tip60 is a novel target in the prevention and treatment of lung cancer.
\end{abstract}

Correspondence to: Dr Dali Tian, Department of Thoracic Surgery, The Fourth Affiliated Hospital of China Medical University, 4 Chongshan East Road, Shenyang, Liaoning 110032, P.R. China

E-mail: liangh120618@163.com

Key words: lung cancer, ATP-binding cassette transporter E1, acetylation, apoptosis

\section{Introduction}

Lung cancer is one of the most common types of malignancy and it had the highest mortality rate globally of all types of cancer among males (1). In 2011, >1.6 million novel lung cancer cases were diagnosed and $\sim 1.3$ million patients with lung cancer succumbed to the disease worldwide (2). Although therapeutic advances, including surgical resection and chemoradiotherapy, have improved the prognosis of patients with lung cancer, the overall survival rates and quality of life remain unsatisfactory. The migration and invasion of cancer cells that results in metastasis presents the greatest challenge to clinical therapy (3). Hence, investigation of the molecular mechanisms of lung cancer cell invasion and migration may provide novel evidence to improve clinical therapy.

ATP-binding cassette transporter E1 (ABCE1) is a member of the ATP-binding cassette transporter family (4). Binding of the ABCE1 protein with the translation initiation factor, prolongation factor or termination factor serves an important function in promoting the recycling of ribosomes $(5,6)$. A number of studies have confirmed that ABCE1 is associated with the proliferation, apoptosis, migration and invasion of lung cancer cells $(4,7)$. However, the mechanism of ABCE1 in the occurrence of lung cancer remains unknown, to the best of our knowledge.

Acetylation modification of proteins participates in a number of biological processes, including genetic transcription, protein-protein interaction, protein stability, and cell proliferation, migration and differentiation (8). Acetylation of proteins may influence their capacity to bind with DNA and their activity and stability, thus resulting in the occurrence of cancer and changing the biological behaviors of tumor cells $(9,10)$. Acetylation or deacetylation of enzymes may affect their transcriptional activity and result in various dysfunctions of genes and proteins, inducing diseases associated with the migration and invasion of cancer cells (11). In a previous study, it was demonstrated that the acetylation rate of ABCE1 was associated with the TNM stage and lymph node metastasis (12). However, whether the acetylation of the $\mathrm{ABCE} 1$ gene is associated with the occurrence of lung cancer remains unknown to the best of our knowledge.

The HIV-1 Tat interactive protein (Tip60) is a lysine acetyltransferase and a member of the MYST family of histone acetyltransferases (13). A previous study revealed that the 
Tip60-histone acetyltransferase complex has a critical role in DNA repair and apoptosis and that Tip60 binds to histone $\mathrm{H} 3$ trimethylated at lysine 9 to activate ataxia telangiectasia mutant kinase (14). Tip60 was demonstrated to be significantly associated with 5-year disease-free survival of patients with primary melanoma or metastatic melanoma (15). In addition, it has been demonstrated that the Tip60 haploinsufficiency observed in breast and prostate cancer allows Tip60 to function as an oncogene (16). The aim of the present study was to investigate how Tip60 may interact with ABCE and whether Tip60 could be a valuable diagnostic and prognostic biomarker and potential therapeutic agent for lung cancer.

\section{Materials and methods}

Cell culture and cell lines. The human lung cancer A549 cell line and the immortalized human bronchial epithelial HBE cell line (as normal control cells) were obtained from the American Type Culture Collection (Manassas, VA, USA). The cells were cultured in RPMI-1640 with $10 \%$ fetal bovine serum (FBS; both Gibco; Thermo Fisher Scientific, Inc., Waltham, MA, USA), $100 \mathrm{U} / \mathrm{ml}$ penicillin and $100 \mu \mathrm{g} / \mathrm{ml}$ streptomycin and maintained in an incubator at $37^{\circ} \mathrm{C}$ and $5 \% \mathrm{CO}_{2}$.

Bioinformatics analysis. In order to confirm which enzyme is responsible for the acetylation of $\mathrm{ABCE} 1$, an acetylation set enrichment based (ASEB) computer program (http://cmbi. bjmu.edu.cn/huac/predict) (17) was used. ASEB can predict not only the acetylation state, but also the responsible lysine (K)-acetyl-transferase (KAT) family. The prediction method was initially established based on the sequence similarity principle. To predict whether lysine sites within a given protein sequence can be acetylated by specific KAT families, the KAT family of interest was initially selected.

Transfection. The sequence of the target gene Tip60-small interfering RNA (siRNA) was as follows: 5'-GGGCACCAT CTCCTTCTTTdTdT-3'. A549 cells were seeded in 6-well plates at a density of $\sim 3 \times 10^{5}$ cells/well. A single cell suspension was prepared using the cells in the logarithmic growth phase and they were washed with RPMI-1640 without FBS twice. The cells were incubated without FBS for $4 \mathrm{~h}$ at $37^{\circ} \mathrm{C}$. The lentivirus-based Tip60-siRNA expression system (Si-1) and the negative scrambled control (Si-N; 5'-CAACAAGAT GAAGAGCACCdTdT-3') were purchased from Guangzhou RiboBio Co., Ltd. (Guangzhou, China). Cell infection was performed using the riboFECT ${ }^{\mathrm{TM}} \mathrm{CP}$ Transfection kit (Guangzhou RiboBio Co., Ltd.) according to the manufacturer's protocol. Briefly, a total of $5 \mu \mathrm{l} 20 \mu \mathrm{M}$ siRNA was added into $120 \mu \mathrm{l} 1 \mathrm{X}$ riboFECT ${ }^{\mathrm{TM}} \mathrm{CP}$ Buffer, and the mixture incubated for $5 \mathrm{~min}$ at $37^{\circ} \mathrm{C}$. Subsequently, $12 \mu \mathrm{l}$ riboFECT ${ }^{\mathrm{TM}}$ $\mathrm{CP}$ Reagent was added into the mixture and it was incubated for $15 \mathrm{~min}$ at $37^{\circ} \mathrm{C}$. The riboFECT ${ }^{\mathrm{TM}} \mathrm{CP}$ mixture was diluted with $1,863 \mu \mathrm{l}$ RPMI-1640 to a total volume of $2 \mathrm{ml}$. The cells were cultured for a further $48 \mathrm{~h}$, at which point the subsequent experiments were performed. The blank control group (N) consisted of untransfected A549 cells.

Co-immunoprecipitation (Co-IP). A549 and HBE cells were lysed on ice with radioimmunoprecipitation assay (RIPA) buffer (Thermo Fisher Scientific, Inc.) and equal amounts of protein $(500 \mu \mathrm{g})$ from the whole cell extracts were pre-cleared with protein $\mathrm{A} / \mathrm{G}$ agarose beads (Thermo Fisher Scientific, Inc.) at $4^{\circ} \mathrm{C}$ for $2 \mathrm{~h}$. Subsequently, the protein was incubated with Immunoglobulin $\mathrm{G}$ (control antibody, dilution, 1:1,000; cat. no. ab172730; Abcam, Cambridge, MA, USA) or ABCE1 antibody (dilution, 1:500; cat. no. ab185548; Abcam) for $24 \mathrm{~h}$ at $4^{\circ} \mathrm{C}$ with gentle shaking. The beads were washed 3 times with $1 \mathrm{ml}$ RIPA buffer, and the immune complexes were eluted by boiling at $100^{\circ} \mathrm{C}$ for $5 \mathrm{~min}$ in $2 \mathrm{X} \mathrm{SDS}$-containing sample buffer. The beads were then washed 3 times using PBS, and $50 \mu \mathrm{g}$ protein per lane was resolved using SDS-PAGE (10\% gel) followed by immunoblotting with anti-acetyl lysine antibody (dilution, 1:5,000; cat. no. ab185548; Abcam) overnight at $4^{\circ} \mathrm{C}$.

Western blotting. Cells were lysed on ice for $20 \mathrm{~min}$ with RIPA buffer and the protein concentration was assessed using a BCA kit (Beyotime Institute of Biotechnology, Haimen, China). The cell lysates ( $\mathrm{Si}-1, \mathrm{Si}-\mathrm{N}$ and $\mathrm{N}$ ) and immunocomplexes were resolved using 12\% SDS-PAGE and electronically transferred onto polyvinylidene fluoride membranes (EMD Millipore, Billerica, MA, USA). Following blocking at $4^{\circ} \mathrm{C}$ overnight with $5 \%$ non-fat milk in Tris-buffered saline with $0.1 \%$ Tween-20, the membranes were incubated with primary antibodies against ABCE1 (dilution, 1:5,000; cat. no. ab185548; Abcam), GAPDH (dilution, 1:10,000; cat. no. AP0063; Bioworld Technology, Inc., St. Louis Park, MN, USA), cyclin-dependent kinase inhibitor 1A (dilution, 1:3,000; cat. no. ab109520; Abcam), caspase 3 (dilution, 1:5,000; cat. no. ab13847; Abcam), MDM2 proto-oncogene (dilution, 1:3,000; cat. no. ab38618; Abcam) and B cell leukemia/lymphoma 2 (dilution, 1:500; cat. no. ab32124; Abcam) at $4^{\circ} \mathrm{C}$ overnight. Subsequently, the membranes were washed three times with TBST buffer. The membranes were then incubated with anti-rabbit (dilution, 1:10,000; cat. no. ab150077; Abcam) or anti-mouse (dilution, 1:10,000; cat. no. ab150113; Abcam) secondary antibodies conjugated to horseradish peroxidase (EMD Millipore) at room temperature for $2 \mathrm{~h}$. The bands were visualized using enhanced chemiluminescence (Thermo Fisher Scientific, Inc.) Densitometry was calculated using Quantity One software 4.6.2 (Bio-Rad Laboratories, Inc., Hercules, CA, USA).

Cell proliferation assay. Cells ( $\mathrm{Si}-1, \mathrm{Si}-\mathrm{N}$ and $\mathrm{N}$ ) were seeded in a 96 -well plate at a density of $5 \times 10^{3}$ cells/well. After 12, 24, 48 and 72 h, $50 \mu 1$ 1X MTT (Sigma-Aldrich; Merck KGaA, Darmstadt, Germany) solution was added to each well and they were incubated for $4 \mathrm{~h}$ at $37^{\circ} \mathrm{C}$. Following centrifugation for $5 \mathrm{~min}$ at $1,000 \mathrm{x} \mathrm{g}$, the supernatant was eliminated and $150 \mu \mathrm{l}$ dimethyl sulfoxide (Beijing Solarbio Science \& Technology Co., Ltd, Beijing, China) was added. The wells were incubated at room temperature for $3 \mathrm{~h}$. Subsequently, the optical density was detected at $570 \mathrm{~nm}$ to form a cell proliferation curve.

Flow cytometric assays of cell apoptosis. The apoptosis of the three groups of cells ( $\mathrm{Si}-1, \mathrm{Si}-\mathrm{N}$ and $\mathrm{N}$ ) was assessed using flow cytometry. The cells were collected following $48 \mathrm{~h}$ of transfection, digested by trypsin without EDTA, and then PBS was used to wash them three times. Subsequently, the cells were collected and fixed in $70 \%$ ethanol overnight at $4^{\circ} \mathrm{C}$, and 
then they were centrifuged for $5 \mathrm{~min}$ at $300 \mathrm{x} \mathrm{g}$ three times in $4^{\circ} \mathrm{C}$. Cells $\left(5 \times 10^{5}\right)$ were suspended in $100 \mu \mathrm{l} 1 \mathrm{X}$ Binding Buffer (part of the Annexin V FITC Apoptosis Detection kit II; BD Biosciences, San Jose, CA, USA) and mixed with $5 \mu \mathrm{l}$ annexin V-fluorescein isothiocynate (Annexin V FITC Apoptosis Detection kit II; BD Biosciences) and $5 \mu$ l propidium iodide (PI; Becton, Dickinson and Company, Franklin, Lakes, NJ, USA) at room temperature. The mixture was then incubated for $15 \mathrm{~min}$ at $25^{\circ} \mathrm{C}$. Subsequently, $400 \mu 1 \mathrm{X}$ Binding Buffer (Annexin V FITC Apoptosis Detection Kit II) was added to each tube and the samples were evaluated using flow cytometry. The data were analyzed with CellQuest software version 5.1 (BD Biosciences).

Wound healing assay. Cells of the three groups ( $\mathrm{Si}-1, \mathrm{Si}-\mathrm{N}$ and $\mathrm{N})$ were plated in 6 -well plates $\left(5 \times 10^{3}\right.$ cells $/ \mathrm{ml}$ per well $)$ with RPMI-1640 and 10\% FBS. After $24 \mathrm{~h}$, the cells were serum deprived and scratched with a $200-\mu 1$ plastic pipette tip to create a linear wound. The monolayer was washed twice with PBS to remove debris and detached cells, and then the cells were exposed to serum-free medium at $37^{\circ} \mathrm{C}$ and $5 \% \mathrm{CO}_{2}$. The wound was observed under an inverted microscope (Leica Microsystems GmbH, Wetzlar, Germany) at x100 magnification at 0, 24 and $48 \mathrm{~h}$. The results are expressed as a spread index, which was determined as follows: Distance migrated by the Si-1-treated cells relative to the distance migrated by the Si-N-treated cells.

Transwell experiments. Migration assays of the A549 cells were performed using a Transwell chamber $(8-\mu \mathrm{m}$ pore size; Corning, Inc., Corning, NY, USA). A549 cells of the three groups $(\mathrm{Si}-1, \mathrm{Si}-\mathrm{N}$ and $\mathrm{N})$ were seeded $\left(2.5 \times 10^{5}\right.$ cells per chamber) into the upper chamber with 1\% FBS RPMI-1640 medium. The lower chamber was loaded with RPMI-1640 medium supplemented with $10 \%$ FBS. Following incubation for $24 \mathrm{~h}$ at $37^{\circ} \mathrm{C}$ in $5 \% \mathrm{CO}_{2}$, the cells on the upper surface of the filters were removed using cotton swabs. All of the migrated cells were fixed at $25^{\circ} \mathrm{C}$ with $4 \%$ paraformaldehyde for $15 \mathrm{~min}$ and then stained for $5 \mathrm{~min}$ at room temperature with $1 \%$ crystal violet solution. Cell migration was quantified by counting the number of stained cells per field in 10 random fields for each chamber under an epifluorescence inverted microscope (magnification, x100). Identical chambers coated with Matrigel were used to determine the invasive potential.

Animal study. A total of 12 female NOD/Scid mice (age, 6-8 weeks; weight range, 18-22 g) were purchased from Beijing Vital River Laboratory Animal Technology Co., Ltd. (Beijing, China) and housed at a humidity of $55 \%$ and a temperature of $26^{\circ} \mathrm{C}$ with a 12 -h light/dark cycle and ad libitum access to food and water. The mice were maintained in a pathogen-free facility. The mice were randomly divided into Si-1, Si-N and N groups ( $\mathrm{n}=4$ per group). A549 cells $\left(5 \times 10^{4}\right.$ cells) infected with Si-1 or Si-N or untransfected cells were injected into the right buttock of each mouse. The tumor volumes were measured every 4 days. Following 1 month, the mice were sacrificed by cervical dislocation and the tumors were dissected and weighed. All animal experiments were performed in accordance with the AVMA guidelines and the guidelines established by China Medical University (Shenyang, China). The present protocol was approved by the Animal Welfare and Research Ethics Committee of China Medical University.

Statistical analysis. Statistical analysis was performed using SPSS software version 19.0 (IBM Corp., Armonk, NY, USA). The measurement data are presented as the mean \pm standard deviation or standard error. Two-group continuous variable comparisons were performed using an unpaired Student's t-test and multiple group comparisons were performed using one-way analysis of variance followed by Student-Newman-Keuls test. $\mathrm{P}<0.05$ was considered to indicate a statistically significant difference.

\section{Results}

Tip60 regulates $A B C E 1$ acetylation in $H B E$ and $A 549$ cells. Co-IP and western blotting were used to confirm the acetylation of ABCE1 in A549 and HBE cells. As presented in Fig. 1A and B, the acetylation of ABCE1 was significantly upregulated in the A549 cells compared with the HBE cells $(\mathrm{P}<0.01)$. In order to investigate the enzyme that regulates the acetylation of ABCE1, ASEB was used to predict that Tip60 has the potential to bind to ABCE1 (data not shown). Western blot analysis and Co-IP were subsequently used to determine that the protein expression levels of Tip60 were significantly reduced in the HBE cells compared with those in the A549 cells ( $\mathrm{P}<0.01$; Fig. 1A and C). RNA interference was then used to knockdown Tip60 in the A549 cells. The results demonstrated that the Tip60 expression levels were significantly reduced in the cells transfected with $\mathrm{Si}-1$ siRNA compared with those in the cells transfected with the negative control Si-N siRNA ( $<<0.01$; Fig. 1D and E). Consistent with a previous study (18), the $\mathrm{Si}-1$ siRNA significantly inhibited Tip60 expression and reduced ABCE1 acetylation compared with the $\mathrm{Si}-\mathrm{N}$ and $\mathrm{N}$ groups $(\mathrm{P}<0.01$; Fig. $1 \mathrm{D}$ and $\mathrm{F})$. Collectively, the results indicate that Tip60 directly regulates the acetylation of ABCE1.

Tip60-siRNA suppresses A549 cell proliferation, invasion and migration and induces cancer cell apoptosis. In order to assess the influence of Tip60 on cell proliferation in lung cancer, an MTT assay was performed. The cells were transfected with siRNA against Tip60 and a negative control. The proliferative ability of the Si-1-transfected cells was lower compared with that of the $\mathrm{Si}-\mathrm{N}$-transfected cells at 48 and $72 \mathrm{~h}$. The MTT assay demonstrated that A549 cell proliferation was markedly suppressed by $\mathrm{Si}-1$ siRNA at $72 \mathrm{~h}$ ( $\mathrm{P}<0.05$; Fig. 2A). Wound healing and Transwell assays were performed to evaluate the suppressive effect of Tip60-siRNA in lung cancer cells. As expected, there was a marked reduction in the wound healing, migration and invasion of the A549 cells transfected with Si-1 siRNA when compared with the control cells $(\mathrm{P}<0.01$; Fig. 2B-D). Downregulation of Tip60 expression and acetylation of ABCE1 inhibits tumor growth. In order to further elucidate how Tip60 and ABCE1 acetylation suppress tumor growth, flow cytometry combined with annexin V-FITC/PI staining was used to analyze cell apoptosis. Notably, the results indicated that cell apoptosis was significantly increased in the cells transfected 


\section{A}

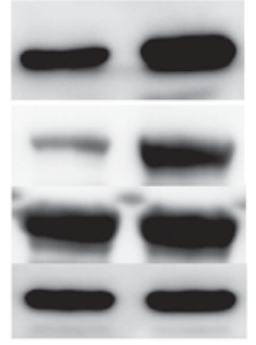

Tip60

Ac-ABCE1

Input: ABCE1

GAPDH

HBE

A549

$\mathrm{C}$

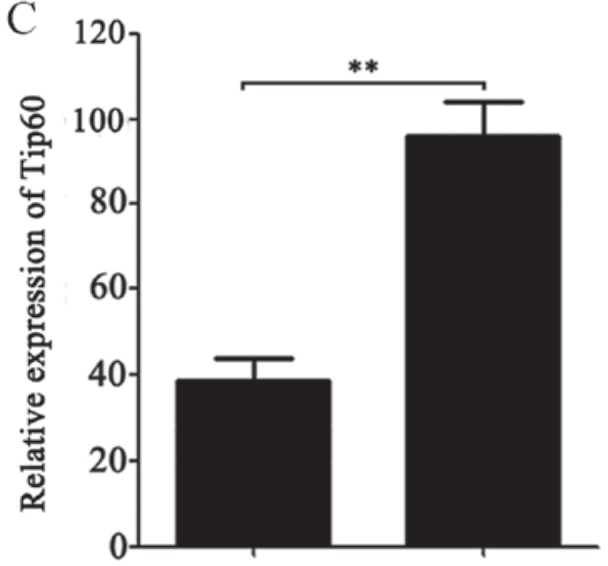

HBE

$\mathrm{E}$

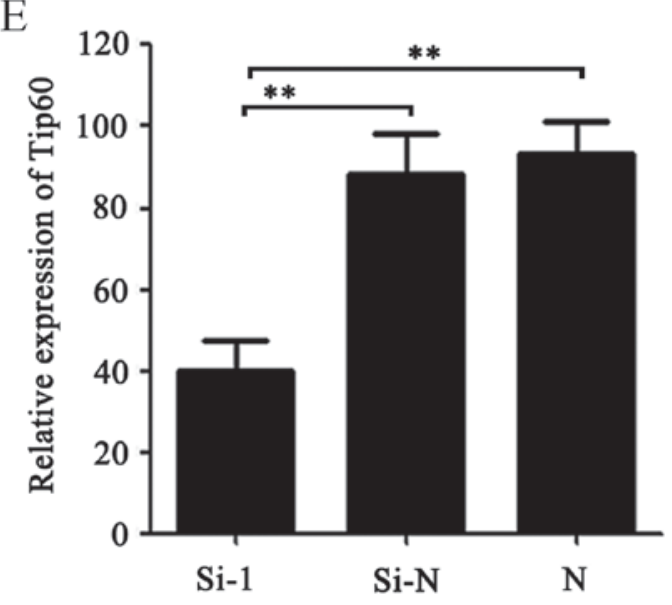

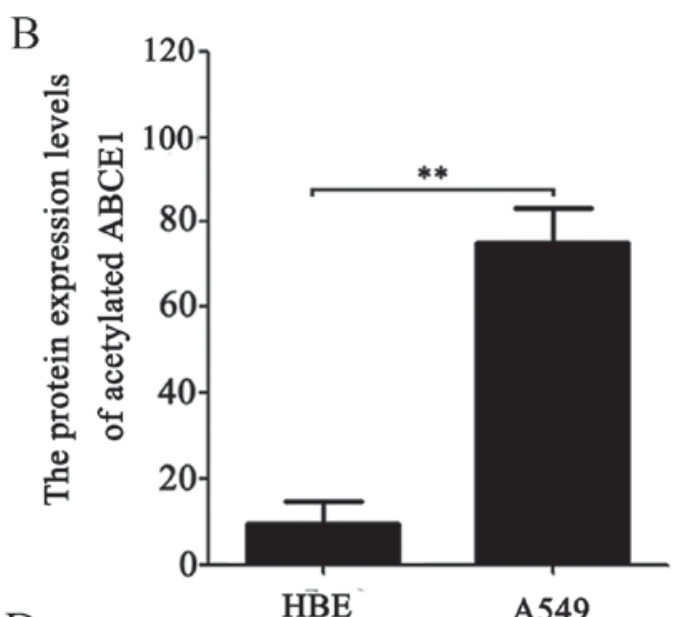

$\mathrm{D}$

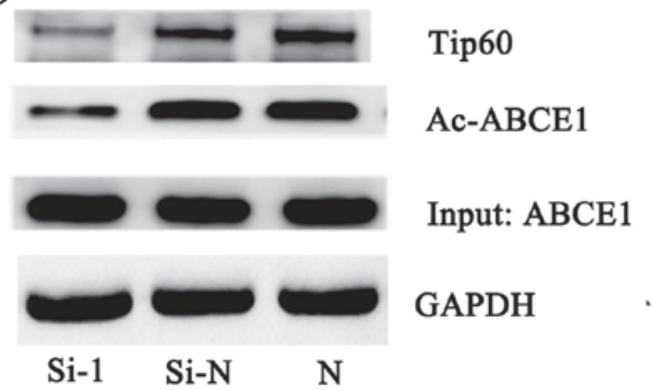

$\mathrm{F}$

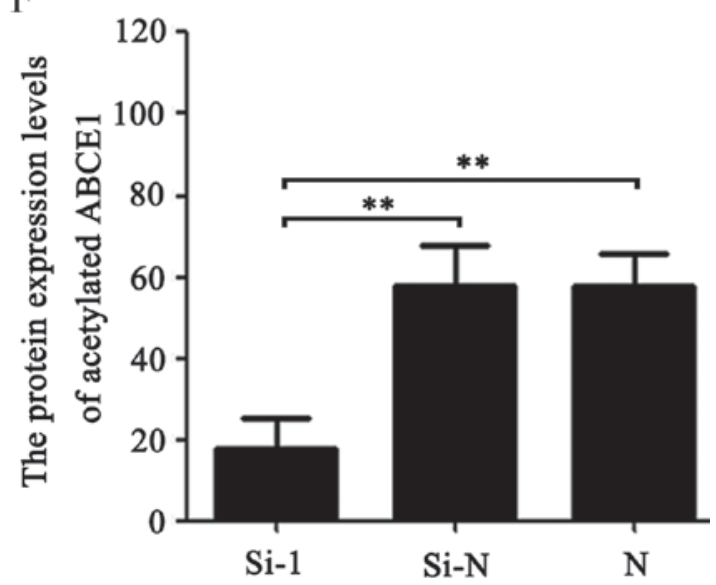

Figure 1. Tip60 regulates ABCE1 acetylation in HBE and A549 cells. (A) Western blotting and co-immunoprecipitation assays were used to determine Tip60 expression and ABCE1 acetylation. The protein expression of (B) Tip60 and (C) acetylated ABCE1 were quantified. Compared with the A549 cells, Tip60 expression and ABCE1 acetylation were downregulated in the HBE cells. (D) Tip60 expression and ABCE1 acetylation were significantly reduced in cells transfected with siRNA. The protein expression of (E) Tip60 and (F) acetylated ABCE1 in the transfected cells was quantified. ${ }^{* *} \mathrm{P}<0.01$ as indicated. Tip60, Tat interactive protein 60 kDa; ABCE1, ATP-binding cassette transporter E1; Ac-, acetylated; Si-1, cells transfected with Tip60-siRNA; Si-N, cells transfected with negative control siRNA; N, untransfected cells; siRNA, small interfering RNA.

with $\mathrm{Si}-1$ siRNA compared with the control groups $(\mathrm{P}<0.05$; Fig. 2E and F).

Tip60-siRNA activates the apoptotic pathway. Western blotting was used to investigate the genes involved in the apoptotic pathway. Downregulating the expression of Tip60 in the A549 cells markedly inhibited MDM2 and BCL2 expression compared with the control cells (Fig. 3). Furthermore, downregulation of Tip60 increased the expression levels of the apoptosis-associated protein p21 and cleaved-caspase 3 in the A549 cells (Fig. 3). Collectively, the results indicate that downregulation of Tip60 expression directly activates the apoptotic pathway to suppress tumor cell proliferation, invasion and migration.

Tip60-siRNA inhibits lung cancer growth in vivo. To confirm whether Tip60 siRNA may serve the same function in the suppression of tumor growth in vivo, a subcutaneous xenograft model was used. Consistent with the in vitro results, downregulation of Tip60 expression significantly reduced the tumor weight $(\mathrm{P}<0.01)$ and markedly decreased the tumor volume compared with the mice injected with control cells (Fig. 4A and B). 
A

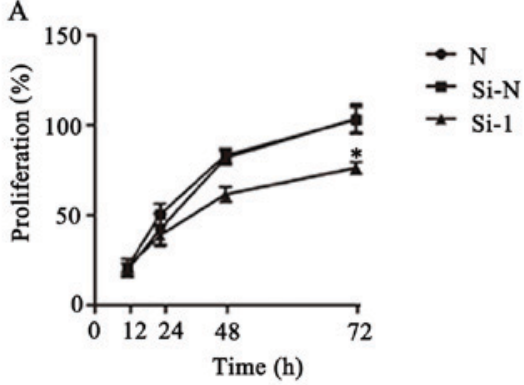

C
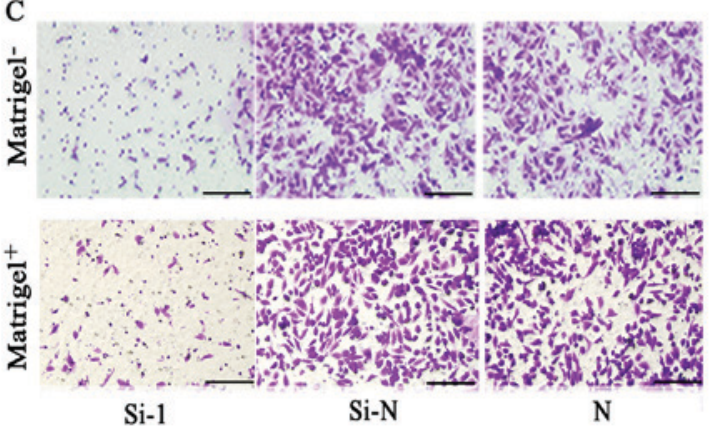

B

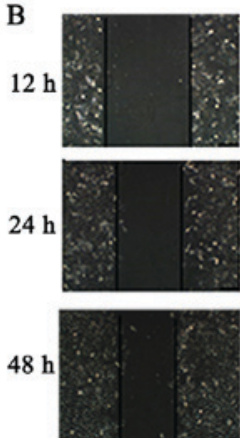

Si-1
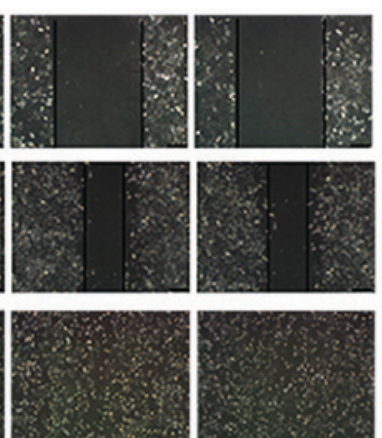

$\mathrm{Si}-\mathrm{N}$

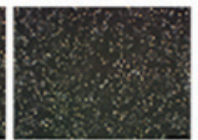

$\mathrm{N}$

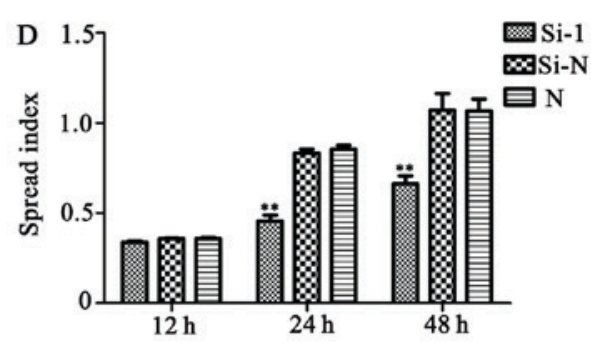

E

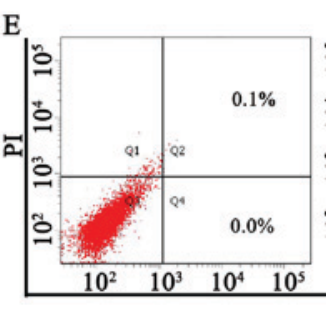

$\mathrm{N}$

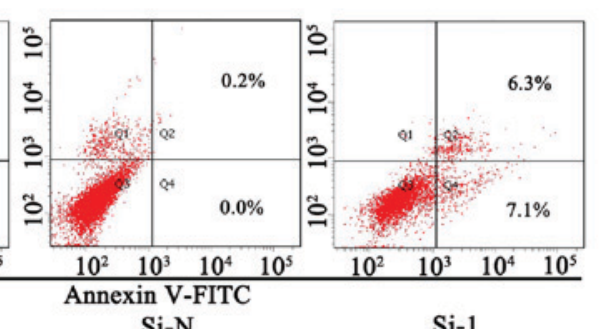

$\mathrm{F}$

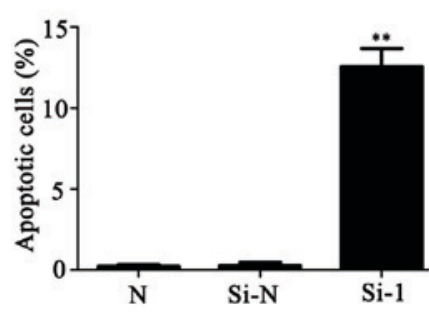

Figure 2. Tip60-siRNA suppresses A549 cell proliferation, invasion and migration and induces apoptosis. (A) The proliferation rate of the Si-1, Si-N and N groups of cells was investigated using an MTT assay. "P<0.05 vs. the Si-N group. (B) Tip60 downregulation inhibited the wound healing ability of the A549 cells. (C) Downregulation of Tip60 expression reduced cell migration and invasion, as observed via a Transwell assay with and without Matrigel. Scale bar, $200 \mu \mathrm{m}$. (D) The spread index of the wound healing assay was quantified. Experiments were performed in triplicate. ${ }^{* *} \mathrm{P}<0.01 \mathrm{vs}$. the $\mathrm{Si}-\mathrm{N}$ group. (E) Decreased Tip60 expression induced apoptosis of the A549 cells. (F) The quantified rate of apoptosis. ${ }^{* *} \mathrm{P}<0.05$ vs. the Si-N group. Tip60, Tat interactive protein $60 \mathrm{kDa}$; Si-1, cells transfected with Tip60-siRNA; Si-N, cells transfected with negative control siRNA; N, untransfected cells; siRNA, small interfering RNA.

\section{Discussion}

Lung cancer is one of the most common types of tumor, with increasing rates of incidence and mortality globally (2). Previously, chemotherapy, radiotherapy and surgery have been used to treat patients with lung cancer; however, traditional treatments have a low remission rate for patients with advanced cancer and often result in negative side effects, including anemia and multiple organ dysfunction syndrome (19). Now that there is a greater understanding of oncogenes, targeted therapies have provided a better choice for patients with advanced cancer. However, resistance and other problems that emerge from targeted therapies in lung cancer exist. Furthermore, a greater number of target genes and mechanisms require elucidation to improve the clinical treatment for lung cancer (20).

There are various types of protein modifications, including acetylation, methylation, ubiquitination and phosphorylation, which heritably regulate gene expression. Acetylation is involved in the majority of cellular biological processes (21). The current evidence indicates that protein acetylation participates in almost all normal vital processes in a cell and serves

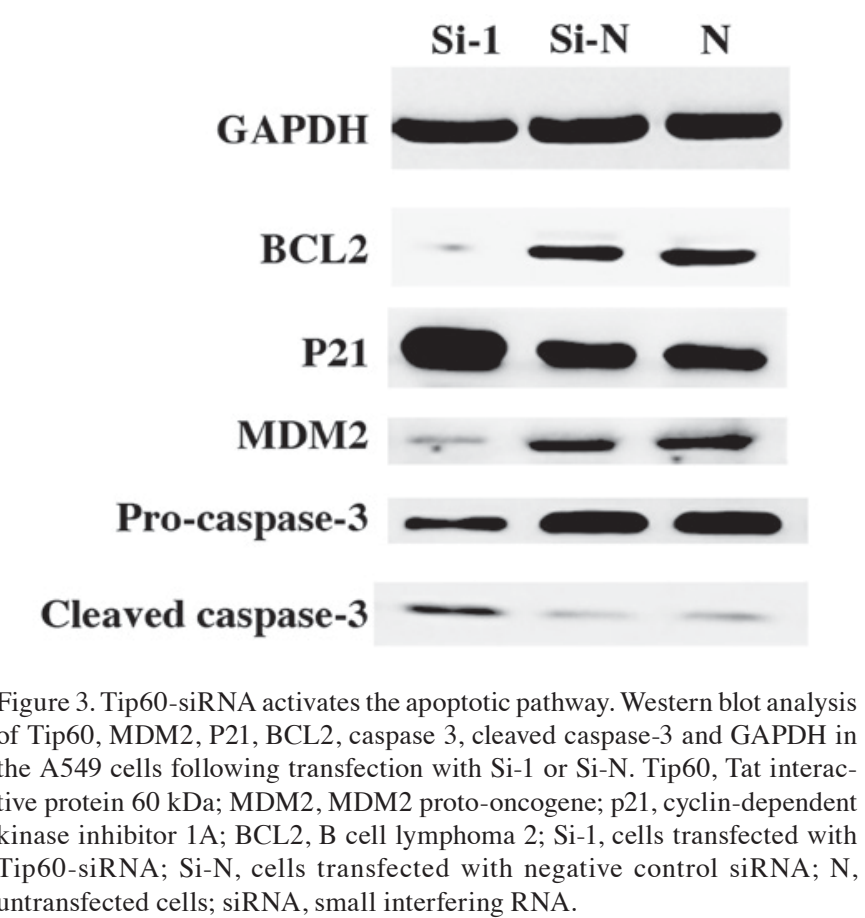



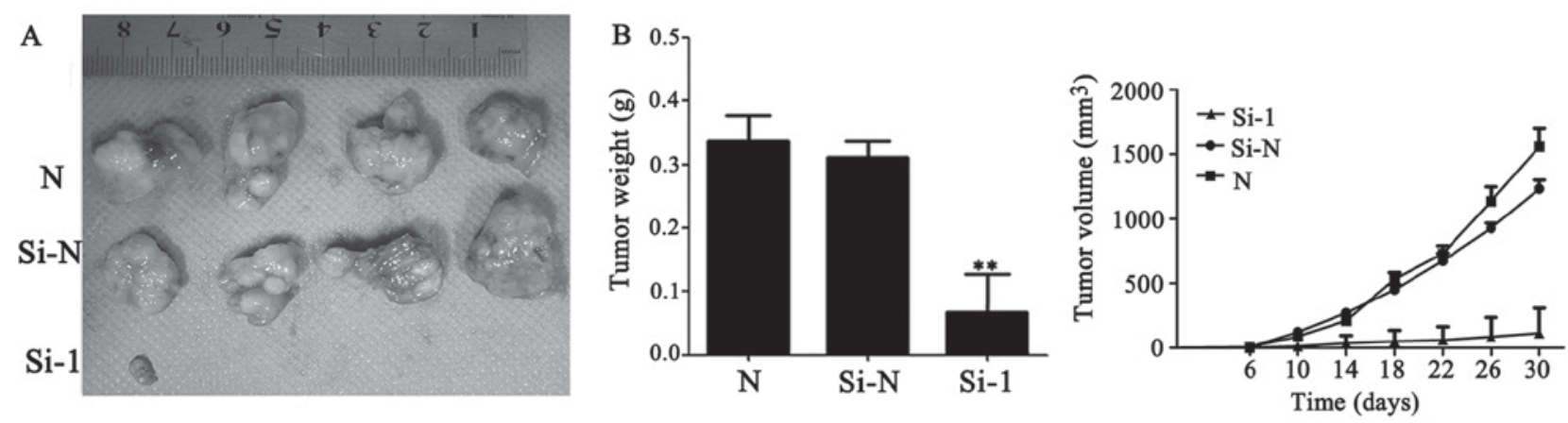

Figure 4. Tip60-siRNA inhibits A549 cell tumor formation and growth. (A) Images of the xenograft tumors from mice injected with Si-1, Si-N or N cells. Following injection of the A549 cells for 30 days, the mice were sacrificed and the xenograft tumors were collected. (B) The tumor weight of the subcutaneous xenografts and growth curves of the tumor volume. ${ }^{* *} \mathrm{P}<0.01$ vs. the Si-N group. Si-1, cells transfected with Tat interactive protein $60 \mathrm{kDa}-\mathrm{siRNA}$; Si-N, cells transfected with negative control siRNA; N, untransfected cells; siRNA, small interfering RNA.

a notable role in initiating a number of events in certain types of cancer by altering gene expression, including regulation of oncogenes and/or tumor suppressors (22-25). Acetylation or deacetylation may influence a wide range of intracellular biological functions, including chromatin stability, the cell cycle, gene transcription and DNA damage repair $(9,10)$. The pathways of non-histone acetylation serve an essential function in tumorigenesis (26). Previous studies have demonstrated that certain types of acetylase may facilitate growth, invasion and chemotherapy resistance of prostate, bladder and lung cancer cells $(27,28)$. As an important member of the MYST family, Tip60 serves a particular role in the acetylation of certain transcription factors and non-histone proteins (12). Tip60 may acetylate K73/K76 of the important transcriptional activator Twist and induce it to bind with bromodomain containing protein 4, which is a member of the bromodomain and extra-terminal family of proteins. This further activates the expression of Wnt family member 5A and thereby upregulates breast cancer cell invasion and tumorsphere formation (29). In prostate cancer, Tip60 promotes cancer cell proliferation via translocation of the androgen receptor into the nucleus, and Tip60 silencing arrests the cell cycle at the G1 phase (18). Additionally, Tip60 regulates the MYC proto-oncogene and amplification of bHLH transcription factors, and participates in events that result in tumorigenesis in various types of human cancer (30). A previous study demonstrated that Tip60 inhibitor may induce cell apoptosis to suppress gastric cancer cell proliferation by increasing the levels of activated caspase-3 and caspase-9 (11). Additionally, Tip60 inactivation reduces the non-histone acetylation levels of certain transcription factors in a DNA-recovered defective nucleus, thus influencing DNA repair and gene mutation and causing cancer (31). In the present study, it was revealed that downregulation of Tip60 may inhibit cancer cell migration and invasion, which is consistent with the results of a previous study (19).

ABCE1 exerts a broad range of functions, which are mainly involved in the translocation of substrates across membranes, but are also involved in translation, DNA repair and chromosome maintenance (5). It has been confirmed that ABCE1 is involved in cell proliferation and anti-apoptotic activity and serves an important role in the translation process (32). Based on the functions of the ABCE1 gene, a previous study suggested that the ABCE1 gene is associated with tumor formation, prognosis and metastasis (7). It has been demonstrated that when the ABCE1-silencing gene is transfected into tumor cells, there is a substantial change in their proliferation and apoptosis (33). A previous study revealed that the expression levels of the ABCE1 protein in lung carcinoma tissues and metastatic lymph nodes are higher compared with those in normal tissues (7). However, how the ABCE1 gene functions as a tumor-associated gene that induces the invasion and migration of tumor cells in lung adenocarcinoma remains unknown. As Tip60 regulates a number of other genes, including EPC1 and DMAP1, and participates in cancer recurrence, further studies are required to fully elucidate the mechanism (34).

The present study, to the best of our knowledge, is the first to demonstrate that ABCE1 is acetylated in lung adenocarcinoma cells and that acetylation of $\mathrm{ABCE} 1$ is rare in normal bronchial epithelial cells, indicating that the occurrence, development and migration of lung adenocarcinoma may be closely associated with acetylation of the ABCE1 protein. Furthermore, a Co-IP assay demonstrated that downregulation of Tip60 reduces ABCE1 acetylation significantly. The results suggest that ABCE1 acetylation may be regulated by the catalytic effect of Tip60 and thereby influence the biological behaviors of tumor cells. An MTT assay and xenograft model were used to assess whether knockdown of Tip60 expression and ABCE1 acetylation were able to inhibit lung cancer cell proliferation and growth in vitro and in vivo. A wound healing and Transwell assay demonstrated that the migration and invasion abilities of lung adenocarcinoma cells were significantly reduced when ABCE1 acetylation was decreased by the downregulation of Tip60. Additionally, western blotting and flow cytometric analysis indicated that Tip60 performs functions via activating the apoptotic pathway. However, although the present study demonstrated that the acetylation of ABCE1 is regulated by Tip60, further studies are required in order to identify the binding site of Tip60. Furthermore, the mechanism by which ABCE1 acetylation regulates the apoptotic pathway of tumor cells remains to be elucidated.

The present study is, to the best of our knowledge, the first to suggest that occurrence and development of lung cancer are associated with the acetylation of the ABCE1 protein. Furthermore, the present study revealed that downregulation of Tip60 reduces ABCE1 acetylation and induces apoptosis of tumor cells. Tip60 may be a key molecule regulating ABCE1 
acetylation in lung cancer cells and therefore may be a promising therapeutic target in advanced lung cancer.

\section{Acknowledgements}

The authors would like to thank the China Medical University Experimental Technology Center (Shenyang, China) for the provision of laboratory equipment.

\section{Funding}

The present study was supported by the Natural Science Foundation of China (grant no. 30973502).

\section{Availability of data and materials}

All data generated or analyzed during the present study are included in this published article.

\section{Authors' contributions}

ZYL designed the study and wrote the manuscript. ZYL and QY performed the experiments. DLT provided the reagents and mice, and provided technical support and conceptual advice. HTJ analyzed and interpreted the data and DLT reviewed and edited the manuscript. All authors read and approved the manuscript.

\section{Ethics approval and consent to participate}

All experimental procedures conformed to the Guide for the Care and Use of Laboratory Animals published by the US National Institutes of Health (NIH Publication No. 85-23, revised 1996) and the study was approved by the Institutional Animal Ethics Committee of China Medical University (Shenyang, China).

\section{Patient consent for publication}

Not applicable.

\section{Competing interests}

The authors declare that they have no competing interests.

\section{References}

1. Ferlay J, Shin HR, Bray F, Forman D, Mathers C and Parkin DM Estimates of worldwide burden of cancer in 2008: GLOBOCAN 2008. Int J Cancer 127: 2893-2917, 2010.

2. Jemal A, Bray F, Center MM, Ferlay J, Ward E and Forman D: Global cancer statistics. CA Cancer J Clin 61: 69-90, 2011.

3. Fiala O, Šorejs O, Pešek M and Fínek J: Immunotherapy in the treatment of lung cancer. Klin Onkol 30 (Supplementum3): S22-S31, 2017 (In Czech).

4. Ren Y, Li Y and Tian D: Role of the ABCE1 gene in human lung adenocarcinoma. Oncol Rep 27: 965-970, 2012.

5. Chen ZQ, Dong J, Ishimura A, Daar I, Hinnebusch AG and Dean M: The essential vertebrate ABCE1 protein interacts with eukaryotic initiation factors. J Biol Chem 281: 7452-7457, 2006.

6. Becker T, Franckenberg S, Wickles S, Shoemaker CJ, Anger AM, Armache JP, Sieber H, Ungewickell C, Berninghausen O, Daberkow I, et al: Structural basis of highly conserved ribosome recycling in eukaryotes and archaea. Nature 482: 501-506, 2012.
7. Huang B, Gao Y, Tian D and Zheng M: A small interfering ABCE1-targeting RNA inhibits the proliferation and invasiveness of small cell lung cancer. Int J Mol Med 25: 687-693, 2010.

8. Creppe C, Malinouskaya L, Volvert ML, Gillard M, Close P, Malaise O, Laguesse S, Cornez I, Rahmouni S, Ormenese S, et al: Elongator controls the migration and differentiation of cortical neurons through acetylation of alpha-tubulin. Cell 136: 551-564, 2009.

9. Zhuang S: Regulation of STAT signaling by acetylation. Cell Signal 25: 1924-1931, 2013

10. Huang W, Wang Z and Lei QY: Acetylation control of metabolic enzymes in cancer: An updated version. Acta Biochim Biophys Sin (Shanghai) 46: 204-213, 2014.

11. Shi M, Lu XJ, Zhang J, Diao H, Li G, Xu L, Wang T, Wei J, Meng W, Ma JL, et al: Oridonin, a novel lysine acetyltransferases inhibitor, inhibits proliferation and induces apoptosis in gastric cancer cells through p53- and caspase-3-mediated mechanisms. Oncotarget 7: 22623-22631, 2016.

12. Teicher BA and Fricker SP: CXCL12 (SDF-1)/CXCR4 pathway in cancer. Clin Cancer Res 16: 2927-2931, 2010.

13. Zhang X, Wu J and Luan Y: Tip60: Main functions and its inhibitors. Mini Rev Med Chem 17: 675-682, 2017.

14. Sun Y, Jiang X, Xu Y, Ayrapetov MK, Moreau LA, Whetstine JR and Price BD: Histone H3 methylation links DNA damage detection to activation of the tumour suppressor Tip60. Nat Cell Biol 11: 1376-1382, 2009.

15. Chen G, Cheng Y, Tang Y, Martinka M and Li G: Role of Tip60 in human melanoma cell migration, metastasis, and patient survival. J Invest Dermatol 132: 2632-2641, 2012.

16. Brown JA, Bourke E, Eriksson LA and Kerin MJ: Targeting cancer using KAT inhibitors to mimic lethal knockouts. Biochem Soc Trans 44: 979-986, 2016.

17. Wang L, Du Y, Lu M and Li T: ASEB: A web server for KAT-specific acetylation site prediction. Nucleic Acids Res 40 (Web Server issue): W376-W379, 2012.

18. Shiota M, Yokomizo A, Masubuchi D, Tada Y, Inokuchi J, Eto M, Uchiumi T, Fujimoto N and Naito S: Tip60 promotes prostate cancer cell proliferation by translocation of androgen receptor into the nucleus. Prostate 70: 540-554, 2010.

19. Socinski MA, Obasaju C, Gandara D, Hirsch FR, Bonomi P, Bunn PA Jr, Kim ES, Langer CJ, Natale RB, Novello S, et al: Current and emergent therapy options for advanced squamous cell lung cancer. J Thorac Oncol 13: 165-183, 2018.

20. Zappa C and Mousa SA: Non-small cell lung cancer: Current treatment and future advances. Transl Lung Cancer Res 5: 288-300, 2016.

21. Martínez-Reyes I and Chandel NS: Acetyl-CoA-directed gene transcription in cancer cells. Genes Dev 32: 463-465, 2018.

22. Lovinsky-Desir S and Miller RL: Epigenetics, asthma, and allergic diseases: A review of the latest advancements. Curr Allergy Asthma Rep 12: 211-220, 2012.

23. Garagnani P, Pirazzini C and Franceschi C: Colorectal cancer microenvironment: Among nutrition, gut microbiota, inflammation and epigenetics. Curr Pharm Des 19: 765-778, 2013.

24. Siegel R, Naishadham D and Jemal A: Cancer statistics, 2013. CA Cancer J Clin 63: 11-30, 2013.

25. Zhang K, Tian S and Fan E: Protein lysine acetylation analysis: Current MS-based proteomic technologies. Analyst 138: 1628-1636, 2013

26. Shanmugam MK, Arfuso F, Arumugam S, Chinnathambi A, Jinsong B, Warrier S, Wang LZ, Kumar AP, Ahn KS, Sethi G and Lakshmanan M: Role of novel histone modifications in cancer. Oncotarget 9: 11414-11426, 2018.

27. Hirano G, Izumi H, Kidani A, Yasuniwa Y, Han B, Kusaba H, Akashi K, Kuwano M and Kohno K: Enhanced expression of PCAF endows apoptosis resistance in cisplatin-resistant cells. Mol Cancer Res 8: 864-872, 2010.

28. Shiota M, Yokomizo A, Tada Y, Uchiumi T, Inokuchi J, Tatsugami K, Kuroiwa K, Yamamoto K, Seki N and Naito S: P300/CBP-associated factor regulates Y-box binding protein-1 expression and promotes cancer cell growth, cancer invasion and drug resistance. Cancer Sci 101: 1797-1806, 2010.

29. Shi J, Wang Y, Zeng L, Wu Y, Deng J, Zhang Q, Lin Y, Li J, Kang T, Tao M, et al: Disrupting the interaction of BRD4 with diacetylated Twist suppresses tumorigenesis in basal-like breast cancer. Cancer Cell 25: 210-225, 2014

30. Patel JH, Du Y, Ard PG, Phillips C, Carella B, Chen CJ, Rakowski C, Chatterjee C, Lieberman PM, Lane WS, et al: The c-MYC oncoprotein is a substrate of the acetyltransferases hGCN5/PCAF and TIP60. Mol Cell Biol 24: 10826-10834, 2004. 
31. Gorrini C, Squatrito M, Luise C, Syed N, Perna D, Wark L, Martinato F, Sardella D, Verrecchia A, Bennett S, et al: Tip60 is a haplo-insufficient tumour suppressor required for an oncogene-induced DNA damage response. Nature 448: 1063-1067, 2007.

32. Huang B, Zhou H, Lang X and Liu Z: siRNA-induced ABCE1 silencing inhibits proliferation and invasion of breast cancer cells. Mol Med Rep 10: 1685-1690, 2014.
33. Qu X and Zhang L: Effect of ABCE1-silencing gene, transfected by electrotransfer, on the proliferation, invasion, and migration of human thyroid carcinoma SW579 cells. Genet Mol Res 14: 14680-14689, 2015.

34. Judes G, Rifaï K, Ngollo M, Daures M,Bignon YJ,Penault-LlorcaF and Bernard-Gallon D: A bivalent role of TIP60 histone acetyl transferase in human cancer. Epigenomics 7: 1351-1363, 2015. 